\title{
Optimization of Internet of Things E-Commerce Logistics Cloud Service Platform Based on Mobile Communication
}

\author{
Jun Chen, Huan Wu (D, Xi Zhou, Maoguo Wu, Chenyang Zhao, and Shiyan Xu
}

SILC Business School, Shanghai University, Shanghai 201800, China

Correspondence should be addressed to Huan Wu; wuhuan@shu.edu.cn

Received 25 January 2021; Revised 25 February 2021; Accepted 1 March 2021; Published 22 March 2021

Academic Editor: Wei Wang

Copyright (C) 2021 Jun Chen et al. This is an open access article distributed under the Creative Commons Attribution License, which permits unrestricted use, distribution, and reproduction in any medium, provided the original work is properly cited.

E-commerce conceivable future trade, consumption, and service is a new digital employer mode. Therefore, in order to decorate the customary natural environment of operation, it is quintessential to get rid of the preferred desktop in the true field, create a social logistics and transportation administration computing device with commodity agents and distributors as the key features, and mix freight logistics, business enterprise approach waft and data waft advertising and marketing, and advertising and marketing organically. The notion of e-commerce logistics looks alongside the enchantment vogue of neighborhood technological knowledge and social demand. It is an integral part of ending e-commerce authentic economic value. All kinds of cell networks clear up the problem of data flow communication; in the technological know-how of telephone network, digital cost solves the bother of capital flow; at present, logistics is however a long-standing problem of e-commerce. Logistics has grown to be the last and entirely bottleneck of e-commerce. If logistics cannot adapt to the enchantment of e-commerce, it may also additionally lead to the slow enchantment of e-commerce. The purpose of this paper is to supply an Internet of things (IoT) e-commerce logistics cloud provider platform based totally absolutely on cell communication, which can be combined with e-commerce and beautify the transport tempo of e-commerce. This paper moreover optimizes the e-commerce logistics system, so that it can combine with e-commerce to increase out the distribution of goods, the distribution tempo of e-commerce is doubled, and e-commerce can in a similar fashion develop rapidly.

\section{Introduction}

The arrival of the technology of e-commerce has considerably promoted the logistics enterprise to the system of statistics and digital development. Logistics e-commerce has grown to be the inevitable style of the future improvement of the logistics industry; however, its future improvement mode and how to depend on technological facts to understand the transformation from bodily logistics to digital logistics want our exploration and lookup [1]. At the same time, as a new trend in the world's manufacturing industry, the Internet of Things technology will inevitably enable manufacturing science to be more completely and thoroughly integrated into human society, thereby providing an upgrade of statistical data for human life style and manufacturing. How to use the web of things technological understanding to promote the enchantment of logistics e-commerce, make the enchantment of logistics organization highly rapid, efficient, and properly timed, and meet the requirements of manufacturing matters to do and decorate the stage of existence service is the main route of the future enchantment of and search for logistics employer [2]. At present, the improvement of China's logistics e-commerce data platform is in the exploration and preliminary stage, and the normal informatization degree of logistics enterprise is noticeably low. The improvement velocity and vogue of logistics e-commerce in China are very obvious, and some achievements have been made in a realistic application. The improvement of logistics e-commerce is inseparable from a suitable logistics e-commerce platform [3]. The rationality and effectivity of platform machine development facts will have an effect on the improvement of logistics e-commerce.

Compared with any time in the past, the recognition of neighborhood and science facts in cutting-edge society has deepened a lot, accompanied by the resource of the 
enchantment of people's material living standards. With the fast improvement of e-commerce, the seamless aggregate of bodily community and digital community of logistics has come to be the major intention of modern-day logistics demand and the improvement path of the logistics industry, displaying the improvement vogue of virtualization; however, its logistics distribution has encountered many obstacles. It is plain that logistics distribution is without delay associated with and restricts the improvement of e-commerce [4]. With the blended software of contemporary logistics and community data provider technology, the mixture of logistics entity community and logistics digital community is turning into greater and extra ideal and progressively integrated. Virtual logistics organizations will grant built-in logistics services, which have ended up in a new vogue of modern-day logistics improvement [5]. In the ordinary logistics distribution enterprises, in order to apprehend the actual searching distribution of a huge broad range of sources to many customers, a massive region of the warehouse is wanted for inventory, and due to the problem of space, the volume and kind of stock are noticeably limited. In the e-commerce system, the document integration of distribution computer can make the digital enterprise be a part of the scattered warehouses belonging to one-of-a-kind owners through the neighborhood desktop [6]. Under the agreed deployment and coordination management, the carrier radius and cargo distribution area are enlarged.

Combined with the modern improvement reputation of e-commerce enterprise logistics in China, this paper frequently researches the third-party logistics from the following aspects: firstly, beginning from the notion of e-commerce logistics and unique e-commerce platforms, this paper researches the logistics provider traits of mainstream e-commerce platforms and then makes additional lookup on the third-party logistics provider of e-commerce and the improvement fame of e-commerce logistics in-depth analysis. Secondly, through the applicable literature and statistical records research, this paper analyzes and summarizes the fundamental troubles in the third-party logistics provider of e-commerce that the modernday pupils are worried about, blended with the evaluation of the participants, finds out the key influencing elements of the third-party logistics provider of e-commerce in China, and attracts the key aspect set desk of the third-party logistics carrier of e-commerce participants. Thirdly, based totally on the similar evaluation of the key influencing elements of e-commerce $1 / 3$ birthday party logistics provider in China, the relationship between the most important elements in e-commerce $1 / 3$ birthday celebration logistics provider device is studied, the causality format of the machine is drawn, then the device dynamics mannequin is established, and the case is proven and analyzed. Based on the evaluation of the full text, this paper places ahead fantastic measures to enhance and optimize the net of matters e-commerce logistics cloud provider platform primarily based on cellular communication. The purpose of this paper is to provide an Internet of things (IoT) e-commerce logistics cloud service platform based on mobile communication, which can be combined with e-commerce and improve the delivery speed of e-commerce. This paper also optimizes the e-commerce logistics system, so that it can combine with e-commerce to carry out the distribution of goods, the distribution speed of e-commerce is doubled, and e-commerce can further develop rapidly.

1.1. Overall Architecture and Functions of E-Commerce Logistics Cloud Platform. The development of the e-commerce logistics cloud carrier platform is based totally on hierarchical architecture $[7,8]$. From the bottom hardware to the top application system, each layer has its own construction objectives and characteristics.

1.2. Overall Architecture and Construction Objectives of the Platform. The logistics platform consists of hardware platform layer, virtual layer, data resource layer, service component layer, service layer, and application layer. The specific structure is shown in Figure 1.

\subsection{Construction Objectives of Each Layer}

1.3.1. Hardware Platform Layer. This layer is the bottom layer of e-commerce logistics cloud service platform, and its construction goal is to build a data center composed of multiple computer clusters and fully connected with a large number of types of IoT terminal equipment, so that the platform has the hardware and software capabilities of fully automatic information collection; whole process status monitoring and massive data processing for ships, vehicles, goods, containers, warehousing, and other logistics resources are the foundation of the project [9].

1.3.2. Virtual Layer. The goal of the virtual layer is to apply the virtualization technology of cloud computing technology to organize and manage all kinds of basic hardware facilities provided in the hardware platform layer, including the IoT terminal equipment and data center physical equipment, and encapsulate them as logical sources with a unified interface to supply quit customers and higher utility features [10].

1.3.3. Data Resource Layer. The development aim of the records of useful resource layer is to follow the large records of parallel storage administration and aid scheduling technological know-how in cloud computing technological know-how to raise out unified, efficient, and safe distributed organization, storage, and management of massive data resources and form a high-performance and scalable data management and scheduling model to support distributed data processing function; it also provides a unified and easyto-use calling interface for the upper application.

1.3.4. Service Layer. The construction goal of the service layer is to write basic web services based on the unified programming interface provided by the data resource layer, which can not only complete specific functions but also provide the upper layer for assembling web service system. 


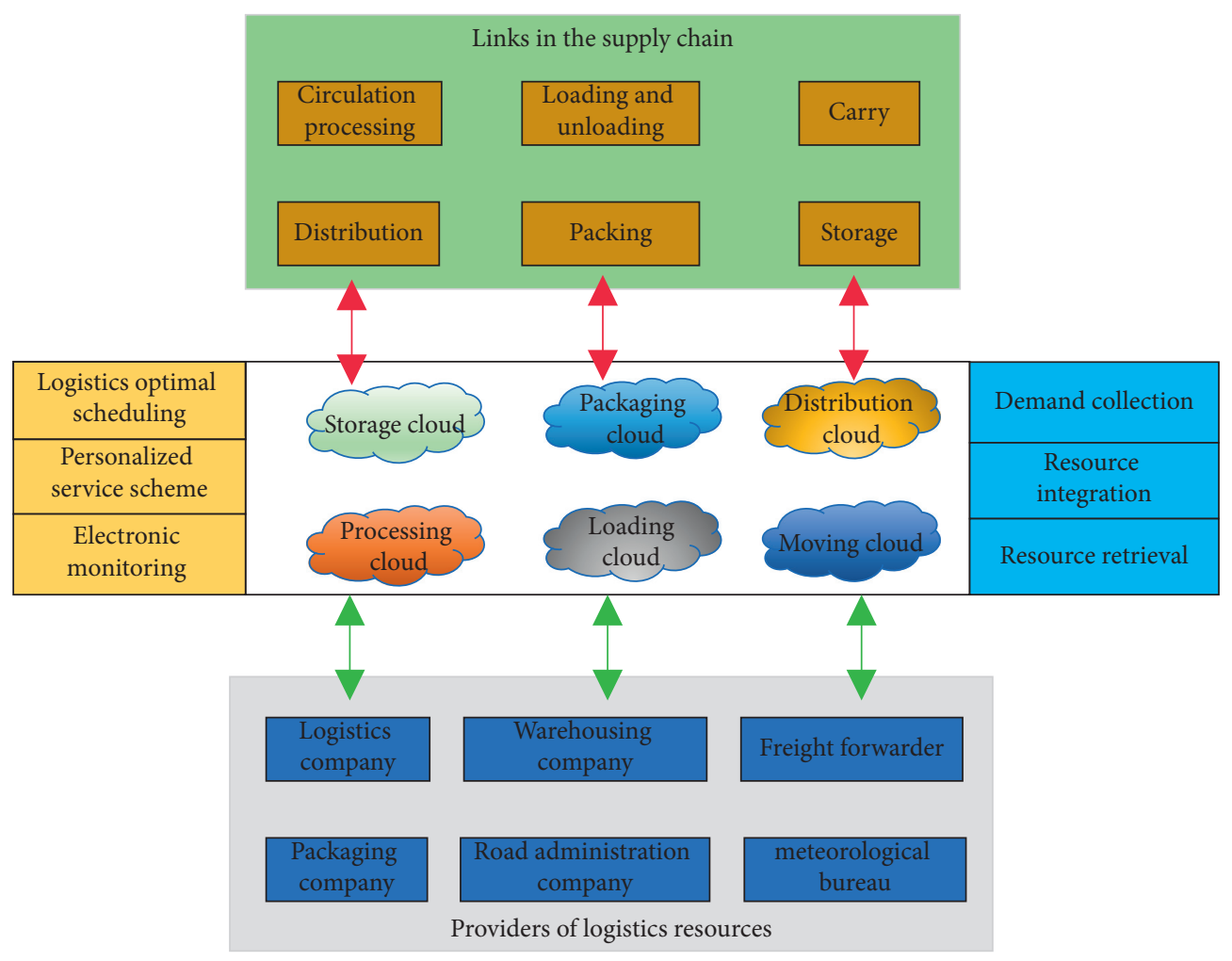

FIgURE 1: Schematic diagram of composite frame.

1.3.5. Service Center Layer. The construction goal of the service center layer is to realize the management and assembly of various web services under SOA architecture [11]. The management of web services refers to publishing, searching, discovering, and monitoring services through the mechanism of service registry; the assembly of web services refers to providing data configuration interface at the business process level through various methods such as work logic and business process and assembling various open and integrated logistics and related services [12].

1.3.6. Application Layer. The construction goal of the application layer is to provide a portal service platform for end users, mainly including logistics service system, information service system, business service system, and government service system [13]. Users distributed in different regions can access related services through client systems on various terminals without downloading, installing, or maintaining any software or hardware. In addition, by providing a service integration interface, the e-commerce logistics cloud service platform can adapt to the size of users and provide a variety of use modes [14]. Small enterprises or individuals can directly use the above application system functions; medium-sized agencies can choose a range of provider elements furnished by way of provider layer and carrier center layer on the platform to construct gadget facts immediately in accordance with their personal statistics processing process; large enterprises can flexibly select the services they need through the configuration interface provided by service center layer and integrate them into their existing information system [15].
1.4. Functions of the System. From the perspective of functional services, the e-commerce logistics cloud service platform includes three subsystems: logistics service system, information service system, and e-government service.

1.4.1. Logistics Service System. The logistics service system mainly completes the implementation and operation of the actual logistics business, tracks and supervises its specific situation, ensures the smooth operation and smooth completion of the entire logistics operation process, and provides safe, reliable, efficient, convenient, and scientific management means for port logistics. The specific business includes ship pilotage, terminal intelligent loading and management, container intelligent gate management, loading and unloading equipment intelligent management, ship automatic identification, port vehicle monitoring and scheduling, cold chain logistics management, and auxiliary decision-making function and business process tracking. With the support of advanced information technology, the logistics service system not only provides traditional logistics services, such as obtaining instant information of goods at any time and dynamically controlling the progress of logistics operation, but also fully improves the quality of logistics services through various auxiliary decisionmaking functions, such as ship transportation route selection, capacity analysis, and container volume analysis, so as to make customers obtain higher satisfaction.

1.4.2. Information Service System. The information service system mainly solves the problem of format conversion between heterogeneous data formats through the 
standardization and standardization of information and ensures the smooth flow of information through EDI electronation and standardization of documents and data, EDI document format derivation, and protocol standard conversion, so as to realize the smooth communication between the platform and logistics enterprises, bonded areas, cargo owners, government departments, electronic port, foreign trade zone, and so on. The data exchange of trade and customs clearance, financial service institutions, and other relevant departments provides value-added services for port logistics, such as information conversion, transfer, and certificate deposit [16].

1.4.3. Business Service System. The business service system provides a trading platform to realize a series of online transaction management functions such as goods procurement, online bidding, order, and return, so that all kinds of enterprises can carry out standardized and electronic international trade and e-commerce.

\section{Subjectivity Analysis and Characteristics of E-Commerce Logistics Cloud Service Platform}

2.1. Demand Analysis of E-Commerce Logistics Cloud Service. From the standpoint of enterprises, below the heritage of "Internet plus" and cloud computing, statistics fragmentation and centralization emerge as common traits of regional logistics informatization. However, the mode of regular single logistics corporation offering logistics offerings for a couple of clients has been challenging to meet the personalized market demand. Modern logistics enterprises must change the enterprise organization mode of the traditional logistics era, actively develop demand-driven and open platform logistics, that is, the operation mode of multiagent cooperation, and integrate social logistics resources to carry out regional logistics service; through the economies of scale, we should reduce the unit cost, realize the long tail effect, and amortize the logistics cost. From the perspective of customers, all logistics activities are driven by customers' needs, and customers' customized needs become diversified under the promotion of network technology.

\subsection{Analysis of the Subjectivity of Logistics Cloud Service.} Combined with the demand of regional logistics collaboration and the characteristics of cloud computing technology, the regional logistics cloud service mode oriented to cloud computing environment is defined as follows: in the cloud computing environment, integrating online platform and offline logistics subject, virtualizing and integrating all kinds of idle logistics resources distributed in the region, forming a regional logistics resource pool, and regional logistics operators design a scheme according to the needs of users to provide regional logistics business. In traditional regional logistics, the main body is the economic organization that directly participates or specializes in logistics activities, including cargo logistics enterprises, first-party logistics, second- party logistics, cooperative logistics enterprises, regional logistics enterprises, storage and transportation enterprises, and cloud service providers. Regional logistics cloud service mode is a service mode that provides information on sharing methods and joint working environment for the logistics situation of interconnected enterprises and regions. It can run the tasks submitted by users in a dynamic and real-time virtual resource pool and realize the value-added service of regional logistics [17]. In the regional logistics cloud service mode oriented to cloud computing environment, the concept of each subject is more abundant. According to the different roles in logistics activities, the subjects of regional logistics cloud service can be divided into three categories: the supplier of logistics, the demander of consumption logistics, and the operator of logistics management. (1) Demand subject: the demand subject refers to the consignor or who does not have logistics resources and expects to exchange the service of the supplier with lower cost and time. (2) Supply subject: the supply subject is undertaken by scattered vehicle owners, logistics parks, third-party logistics enterprises, and other entities with logistics resources, as well as financial and insurance institutions. It provides actual logistics services for the demanders and realizes value-added in the form of leasing and transferring logistics resources. (3) Operator: the operator is the regional core leading logistics enterprise, which integrates, dispatches, and optimizes the online services for the demanders and suppliers within a limited time, and collects certain service management profits. There is a relatively equal cooperative relationship between the operation subject and other subjects, which provides users with integrated online logistics services through resource sharing, information integration, collaborative operation, and other solutions. The relationship between the relevant subjects is shown in Figure 2.

Operators set up regional logistics cloud carrier platform and always enhance the characteristic of cloud platform. Logistics carriers register and $\log$ in to the cloud carrier platform to structure a cloud pool of logistics resources. Demanders register and log in to the cloud provider platform to build a logistics demand order library. It is possible to initiate and question applicable logistics equipment, requirements, and carrier facts through the cloud provider platform [18]. Operators integrate the logistics demand in a period of time and space, form the optimal logistics service scheme, allocate various logistics resources of logistics suppliers according to orders, form a logistics chain, and ensure the efficient coordination of the whole chain logistics. Therefore, from the perspective of service orientation, the fourth party logistics service is closer to the service mode of this paper, both of which emphasize openness, dynamic, sharing, and integration.

2.3. The Process of Logistics Cloud Service. In the technique of regional logistics cloud service, the principal physique is complex, the house is wide, and the market demand is changeable. If there is no scientific corporation method, it 


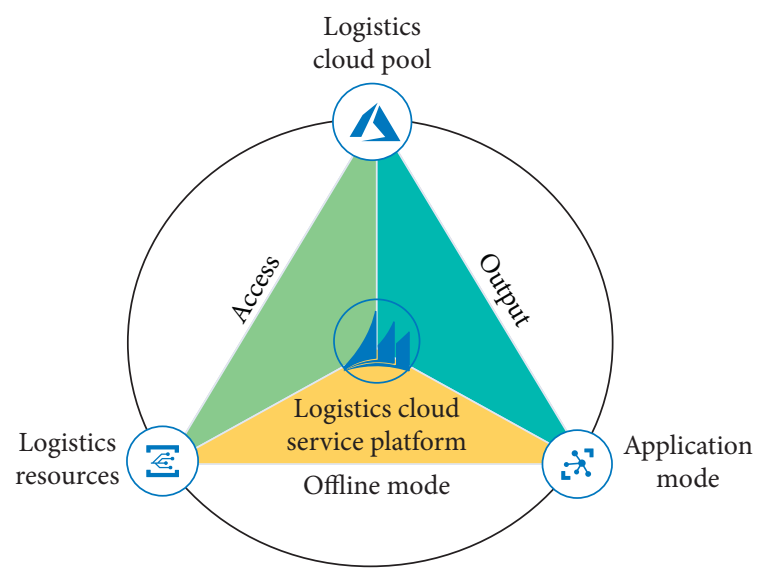

FIgURE 2: Analysis of the subjectivity of logistics cloud service.

might also lead to the imbalance of hobbies among the predominant physique of regional logistics [19]. The manner of regional logistics cloud carrier is proven in Figure 3.

Firstly, the logistics demand is confirmed according to the customer's order, and the demand is decomposed into several feasible subtasks; then, the logistics capability of cooperative logistics enterprises is evaluated according to the logistics distribution task, and the logistics enterprises that meet the capability requirements get the task through bidding [20]. If the logistics enterprise does not meet the capability requirements, it searches through the cloud platform and uses the supplier matching algorithm of regional logistics distribution to calculate the matching degree and complete the decision. All participants in the logistics cloud service are dynamically self-organized to form a regional logistics coordination service chain and provide a high-quality regional logistics service scheme for customers. The cloud service mode of regional logistics express is shown in Figure 4.

Regional logistics enterprises directly receive the order information of logistics consumers and analyze the carrying capacity information of cooperative logistics enterprises. If the carrying capacity meets the order requirements, they directly release the scheduling information to the cooperative logistics capacity unit; otherwise, they analyze and match again [21]. Logistics consumers can send the goods to the designated receiving point by themselves or wait for the cooperative logistics transportation unit to pick up the goods. The realization method of regional logistics service should be designed and implemented according to the types of various logistics resources, the existing businesses of enterprises, and the customized contents proposed by users. Figure 5 describes the process and method of implementing regional logistics distribution cloud service.

The logistics enterprise is a nonstop 24-hour industry, with ubiquitous data grasp and series terminals, gathering records for the logistics enterprise all the time. How to decrease the scale of mass logistics facts besides dropping its cost and how to extract excessive value-added statistics from it for upkeep are the first troubles to be solved in the new era of logistics administration system. With the improvement of personalization and informatization of the logistics industry, it is greater and extra necessary to meet the personalized and different wishes of logistics carrier demanders with excessive efficiency, excessive pace, and excessive quality. In order to highly meet the wishes of logistics carrier demanders, resource integration and effective allocation in logistics enterprises are also interrelated. The integration and distribution of logistics assets generally include mergers and acquisitions and strategic alliances as well as useful resource sharing platforms. Its openness, collaboration, and efficiency are widely recognized. With the improvement of cloud logistics, logistics sources are embodied in the shape of cloud logistics services. Customers search and achieve the required logistics offerings through the cloud logistics provider platform and recognize the allocation and use of cloud logistics assets going through logistics duties below the operation of the platform [22]. Cloud logistics provider platform is record storage and carrier center constructed by way of an expert third-party operation carrier issuer underneath the cloud computing platform. It participates in the audit and administration of logistics resources, integrates logistics sources and purchaser resources, virtualizes logistics assets into logistics offerings for storage and configuration, and customizes and offers clients safe, efficient, high-quality, low-cost, bendy, and variable customized logistics, offering the new logistics carrier mode of logistics. Through the description of the cloud logistics carrier platform, it is now not challenging to locate the following variations between cloud logistics carrier platform and normal logistics carrier platform. Figure 6 indicates the distribution method in the e-commerce logistics cloud.

(1) Cloud logistics provider platform is extra bendy to deal with logistics tasks, which can meet the varied wishes of logistics tasks. Compared with the regular single and restrained logistics service, cloud logistics carrier platform integrates the logistics assets of logistics useful resource providers and can cooperate with logistics assets to lift out logistics things to do in accordance to the customized logistics provider demand, so as to grant an environment friendly and built-in logistics carrier chain.

(2) Cloud logistics carrier platform integrates the scattered logistics assets and improves the utilization price of logistics resources. Based on the logistics assets below the cloud logistics provider platform, which have the traits of decentralization, move organization, and move region, the cloud logistics carrier platform makes use of virtualization science to put the dispersed logistics resources, transportation, and storage ability into the cloud logistics aid pool for unified management and whole the operation cooperatively. Under the mode of cloud logistics provider platform, via cloud computing technology, the present logistics aid providers' logistics assets and logistics competencies are virtualized and built in to structure a cloud logistics aid 


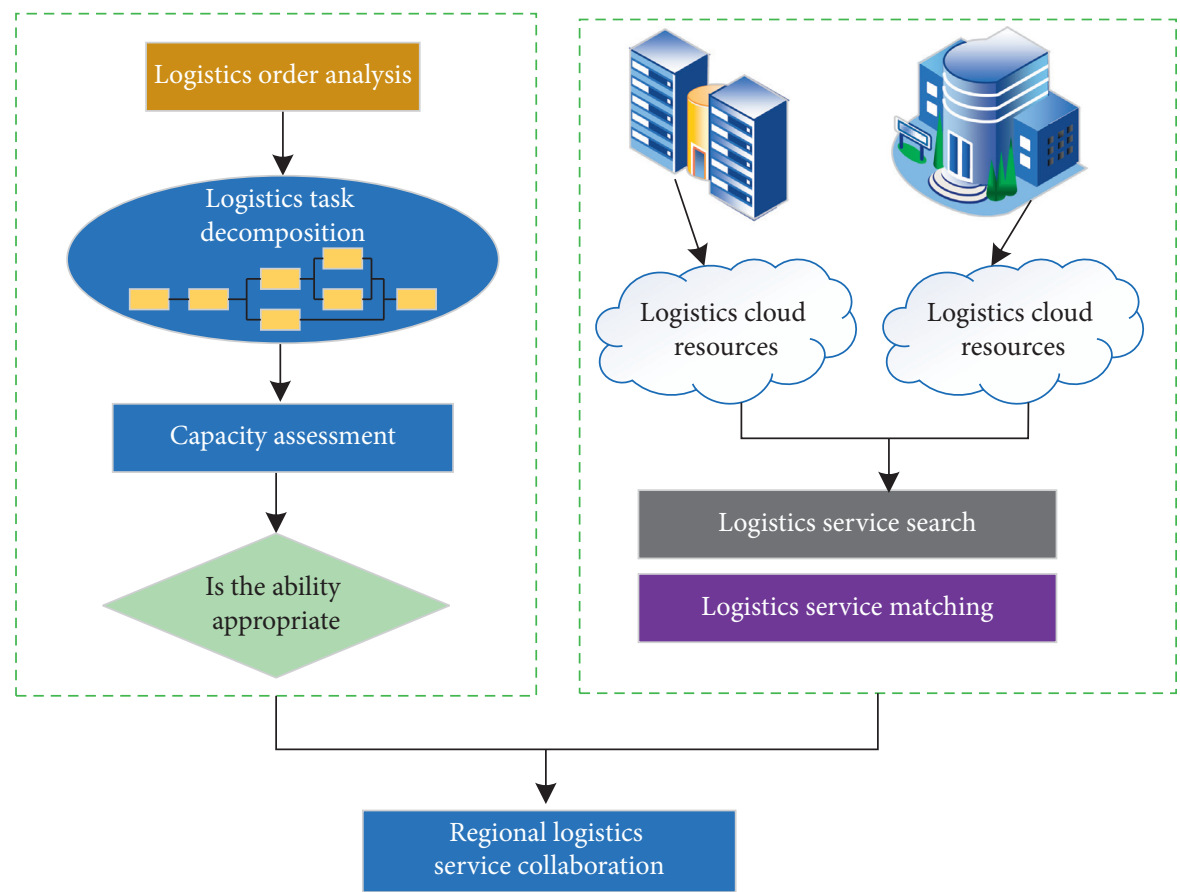

FIgURE 3: Service process of regional logistics cloud.
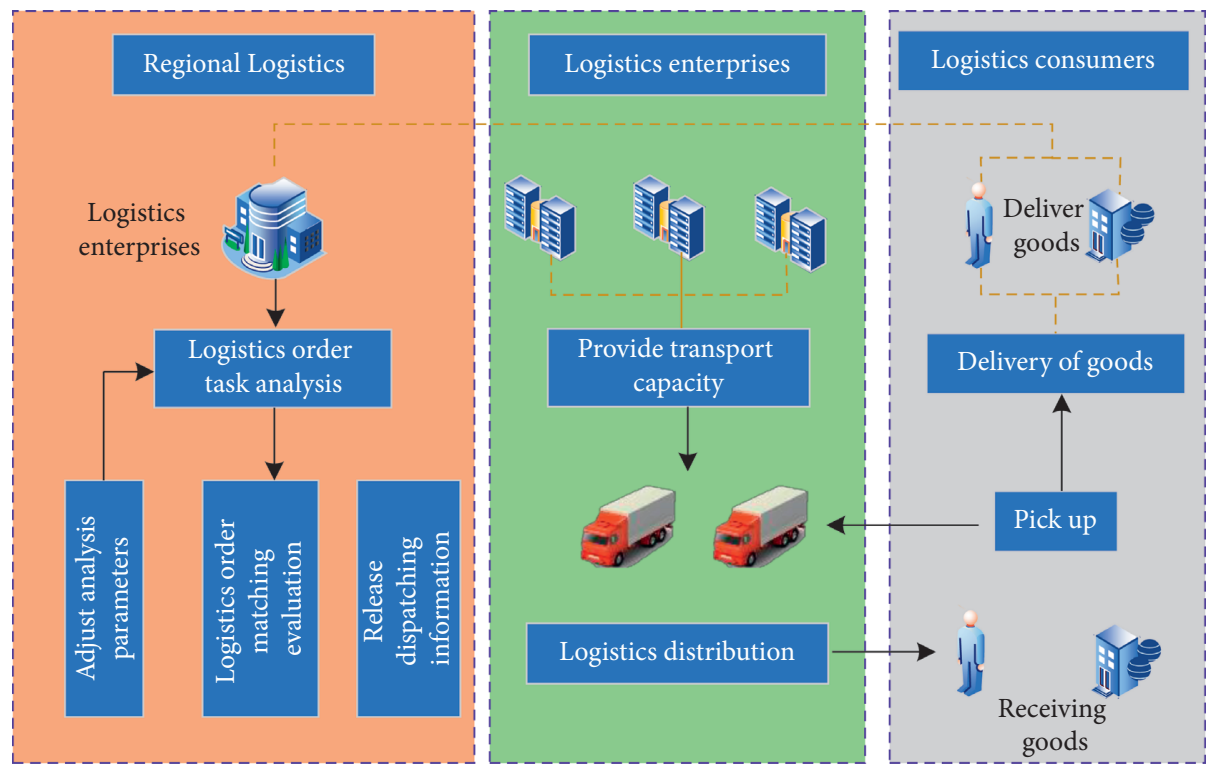

Figure 4: The mode of regional logistics collaborative distribution service.

pool. According to the personalized wants of logistics carrier demanders, an entire logistics aid carrier furnish chain is formed.

(3) Cloud logistics provider platform video displays units, manages the entire existence cycle of logistics tasks, and improves the first-class of logistics services. The cloud logistics provider platform begins the logistics mission things to do after the feasibility planning and evaluation of the logistics task. The logistics carrier demander can reveal the total logistics things to do in actual time via GPS, RFID
$[23,24]$, and different technologies. After the logistics distribution activities, clients can remark on the logistics provider quality.

2.4. Simulation Experiment and Result Analysis. In order to affirm the rationality of the proposed logistics cloud challenge scheduling mannequin based totally on cellular conversation and the effectiveness of the algorithm, a simulation scan is carried out. In order to enforce the simulation, the mannequin is simplified, and the complicated multiobjective 


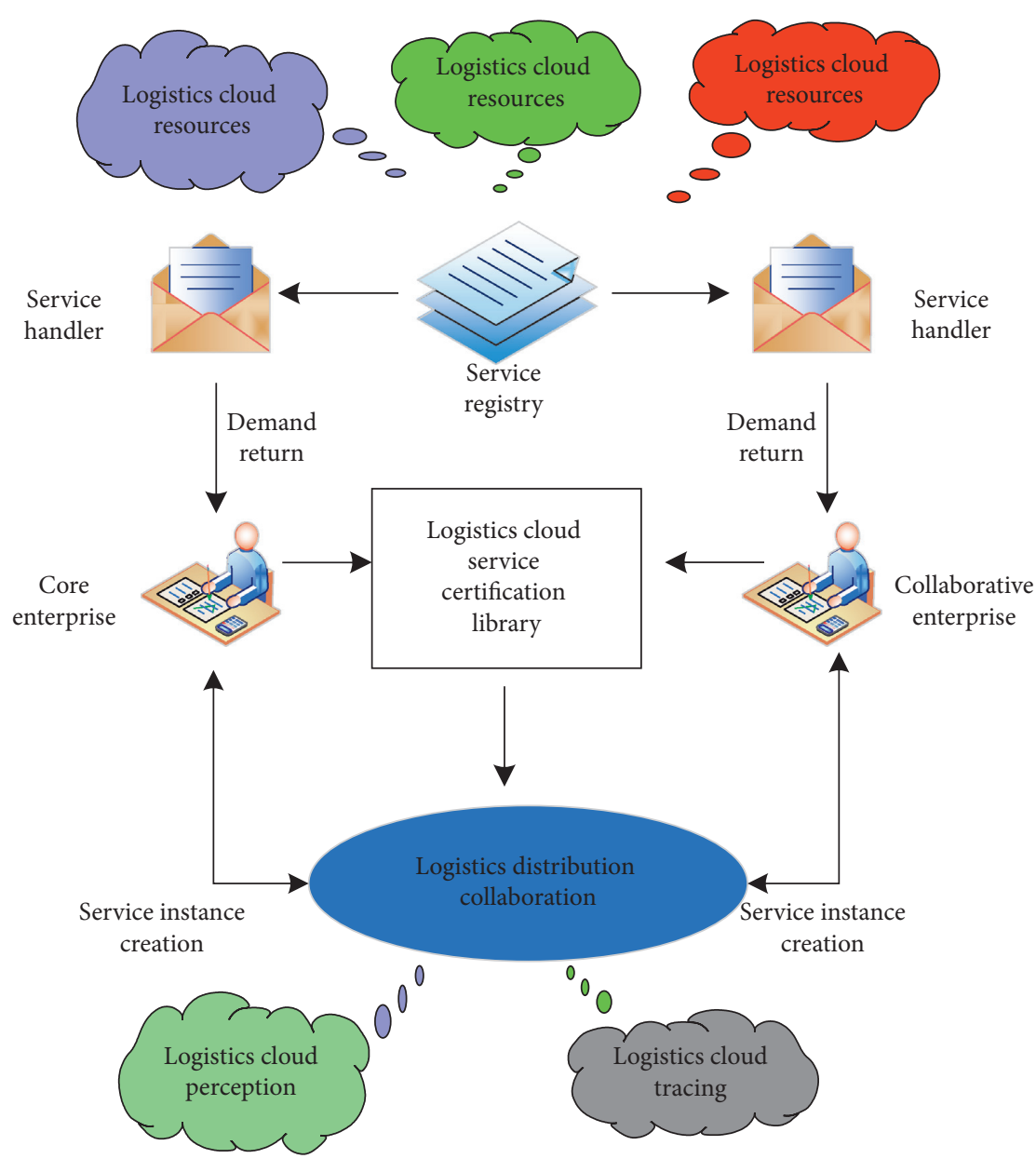

FIGURE 5: Cloud service process of regional logistics distribution.

optimization trouble is changed to a single goal optimization trouble via the desire vector.

2.5. Test and Analysis of Convergence Rate. The genetic algorithm and open-source algorithm on Python are used to simulate the model proposed in this paper. Set the maximum service time of 12 hours per day, select the preference vector as $\lambda(0.4,0.4,0.2)$, and pay more attention to the scheduling time and resource utilization. The optimal scheduling scheme is obtained by simulation, as shown in Figure 7.

Figure 7(a) shows the change of scheduling cost, from which we can see that the cost in the scheduling process gradually decreases with the increase of algorithm iterations, from the initial unit cost of nearly 200 to 120 . Then it gradually decreased to about 80 . The genetic algorithm shows the ability of efficient and accurate solution in these 100 generations of iterations. Figure 7(b) shows the total time trend. It can be seen from the figure that the total time decreases rapidly with the number of iterations, from more than 1000 at the beginning to about 500 at last, and keeps stable for a period, reducing by $50 \%$. From the above simulation results, the fitness function value can converge after 100 generations of iterative calculation using the genetic algorithm described in this paper.

The model is solved by randomly generated initial particle swarm optimization with a scale of 30 . The simulation results are shown in Figure 8. After meeting various constraints, a complete set of nondominated solution sets can be obtained. The average total price of logistics service is 27490 yuan and the service time is 19 days. The average price of the nondominated solution is 18870 yuan, and the service time is about 17.5 days. When the population reaches 1000 generations, the average price of the noninferior solution set logistics service is 17750 yuan, and the service time is about 15.7 days.

2.6. Optimization Results of Line Load Rate. When the initial demand and quotation of each route are known, we can get the capacity of each route in the initial state, initialize the population by solving the feasible solution randomly, and cross and mutate within the scope of the feasible solution. In order to ensure the diversity of the solution, the following results are obtained through MATLAB calculation: after the optimization calculation, the overload demand of the 


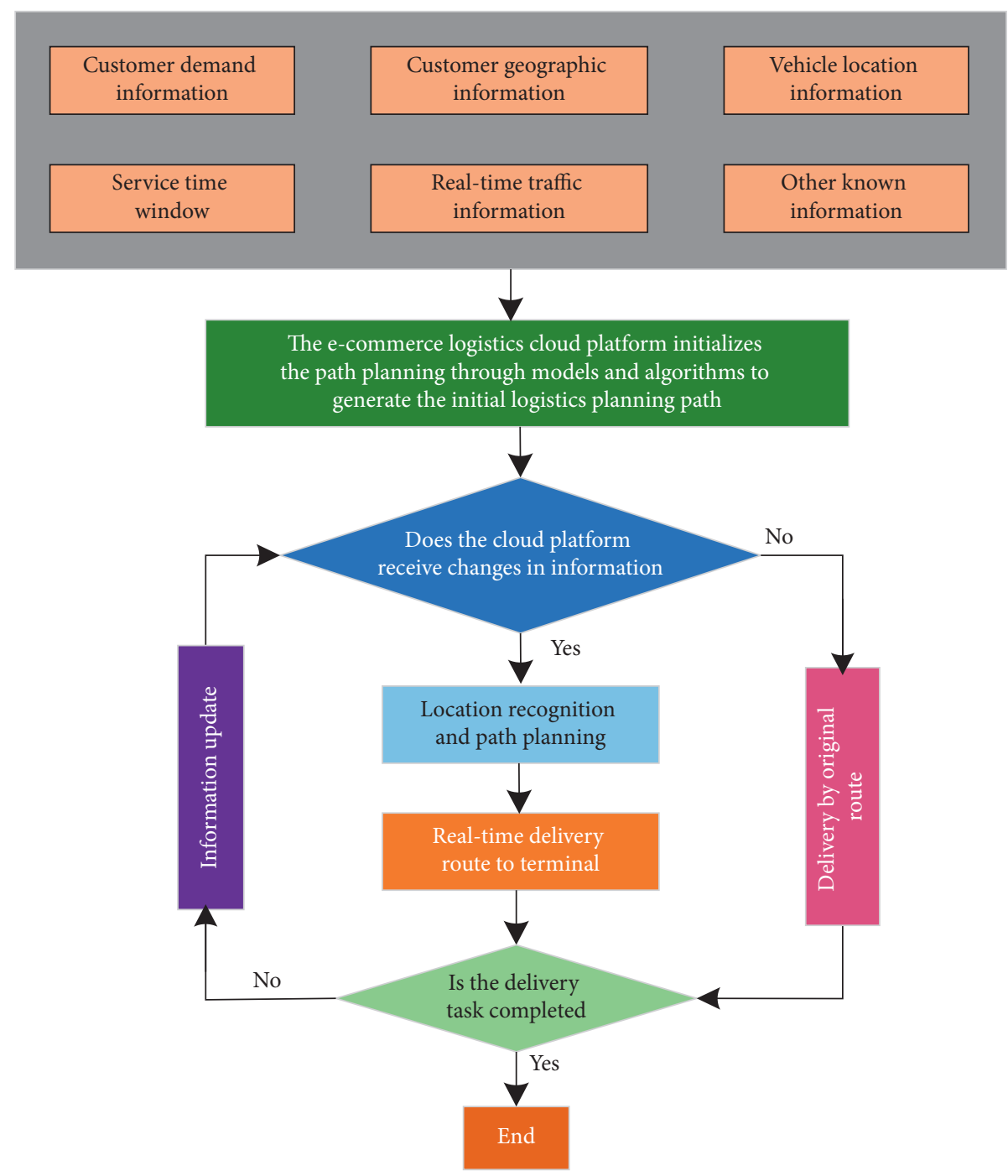

FIgURE 6: Distribution process in e-commerce logistics cloud.

transportation demand distribution can be adjusted to zero transportation.

Figure 9 shows the comparison of load rate before and after optimization. The data calculation and analysis of particle swarm optimization algorithm are more complex, and MATLAB has a powerful matrix operation function and graphical display function, so this example writes program code on the mathematical simulation software MATLAB to realize the solution of particle swarm optimization algorithm. The algorithm parameters are set as follows: the population size is 30 , the external set size is 50 , the maximum number of iterations is 1000 , and the maximum number of cooperative enterprises is 5 .

The simulation results in Figure 10 show that the multiobjective optimal service composition algorithm based on improved particle swarm optimization has better convergence and better solution effect. Finally, we find that there are 30 Pareto optimal solutions, and all solutions in the outer set are nondominated and uncorrelated. The solutions in the solution set are put into the graph according to the grid. The grid width in the figure is 0.4 and 400 , respectively, resulting in 25 grids. The solutions are basically published in seven of them. From the front-end curve of nondominated solutions, the lowest price of 30 solutions is 16580 , the highest price is 18500 , the average is 1775 , and the service time is 15 days to 17.5 days. The difference of objective function value of the nondominated solution is small, especially for the solution in the same grid, the difference of service price is only 400 yuan at most, and the difference of service time is more than 3 hours at most. In order to promote the healthy development of the logistics service industry, when presenting the query results of the service portfolio to customers, the presentation of time and price 


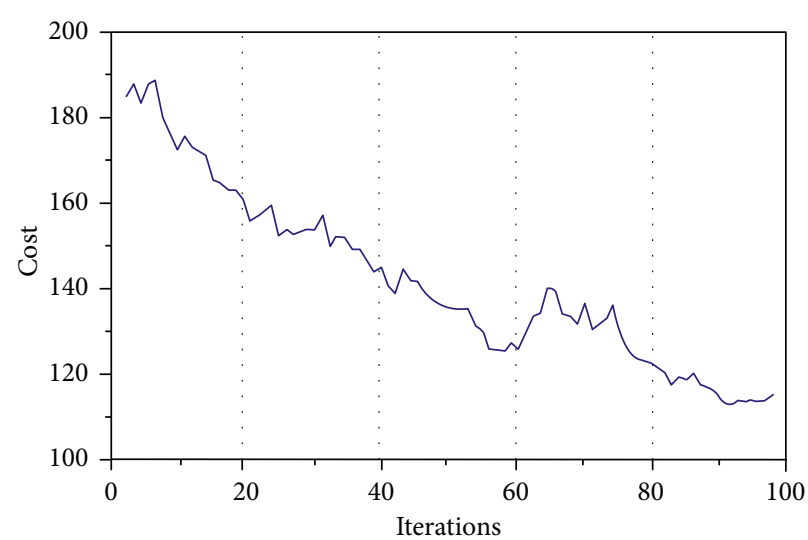

(a)

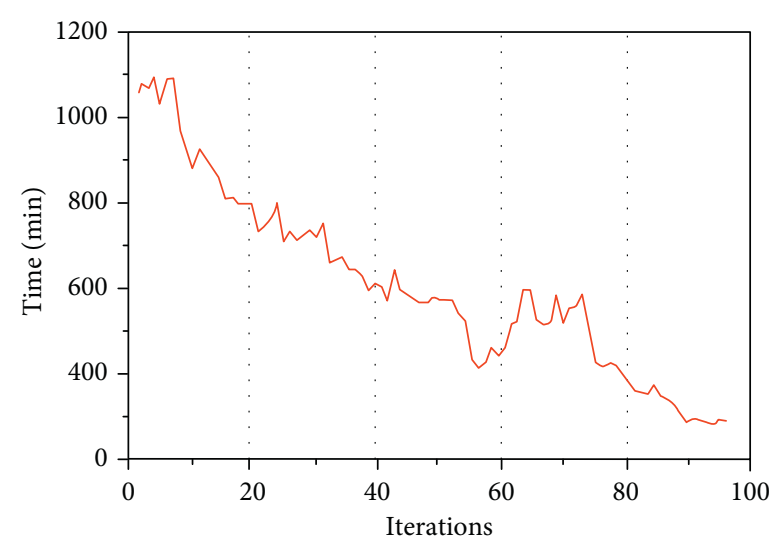

(b)

FIgURE 7: Test and analysis of convergence rate. (a) Change chart of dispatching cost. (b) Trend chart of the total time change.

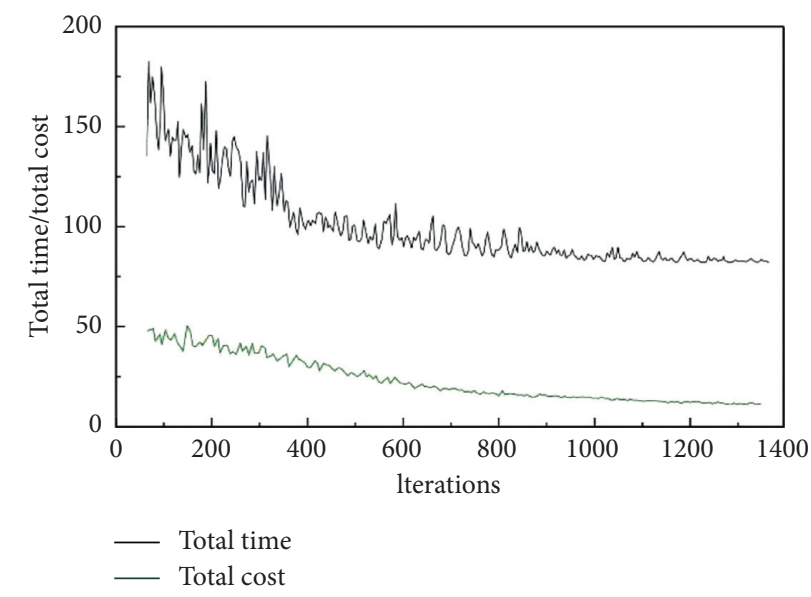

FIGURE 8: Mean change curve of population objective function.

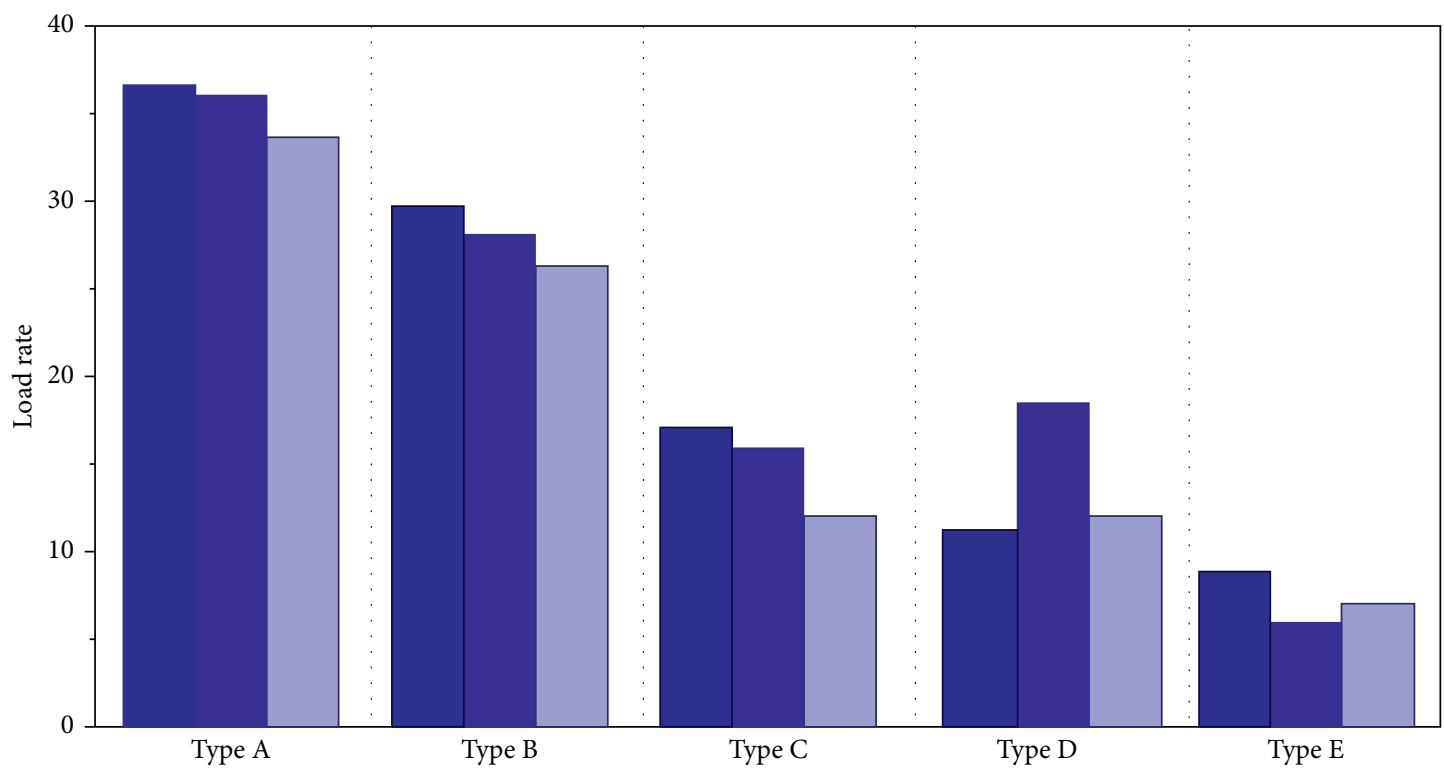

(a)

Figure 9: Continued. 


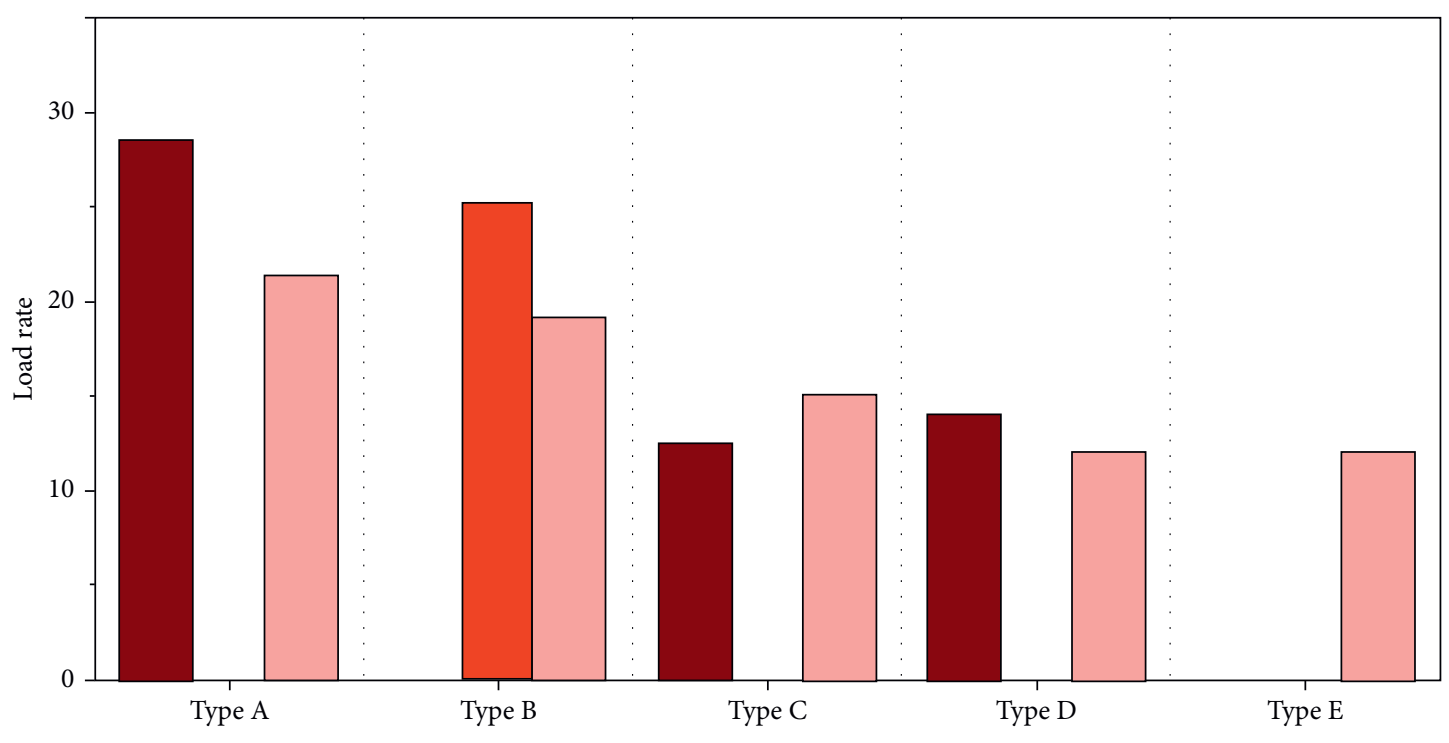

(b)

FIGURE 9: Comparison of load rate before and after optimization. (a) Load rate before optimization. (b) Load rate after optimization.

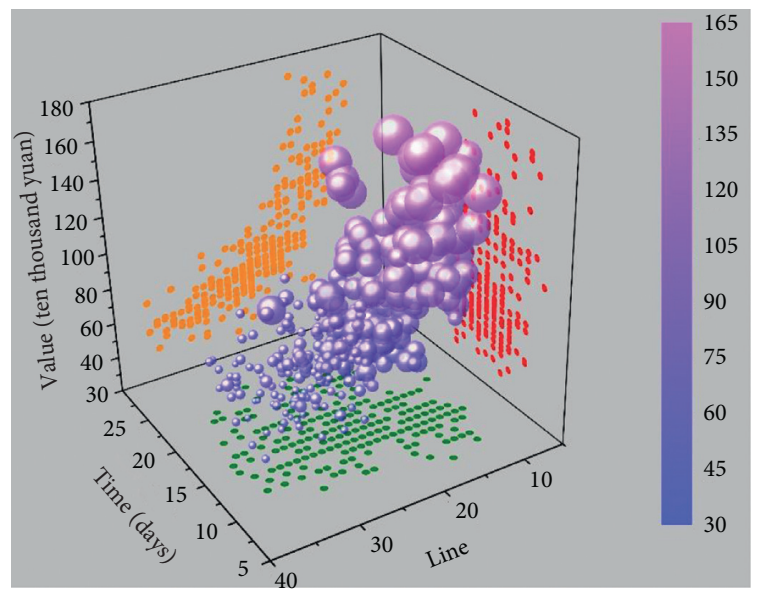

Figure 10: Value distribution of objective function after optimization.

should be handled slightly, and the service portfolio in the same grid should be sorted according to the degree of complementarity.

\section{Conclusion}

This paper researches the key applied sciences of the net of matters e-commerce logistics cloud carrier platform primarily based on cell communication, respectively, from the regional logistics cloud provider mode beneath the e-commerce logistics cloud, virtualization integration method, and logistics distribution provider chain optimization. Firstly, the thinking of regional logistics cloud carrier mode is put forward, then all sorts of topics in regional logistics cloud carrier are analyzed, and the regional logistics collaborative framework dominated by means of core logistics agencies is proposed. Secondly, the demand of regional logistics record asset integration and sharing beneath the cell Internet surroundings is analyzed, and on this basis, the dispensed statistics mannequin of regional logistics record asset based totally on the meta mannequin is proposed and the virtualization approach of regional logistics fact asset for cloud computing surroundings is studied. The innovation of this paper lies in the design of logistics distribution based on the cloud logistics service platform. According to the predictability of the logistics platform to the logistics orders, the logistics resource providers plan the specific tasks of distribution according to their own tasks and the relevant needs of distribution before carrying out the specific distribution. At the same time, considering the spare vehicles in the process of distribution, information about the type, capacity, and distribution of acceptable commodities can be released through the platform. According to the characteristics of logistics distribution under cloud logistics service platform, this paper puts forward a cooperative distribution mode based on logistics resource provider and establishes a cooperative distribution model, which has a great contribution.

\section{Data Availability}

Data sharing is not applicable to this paper as no datasets were generated or analyzed during the current study.

\section{Consent}

Informed consent was obtained from all individual participants included in the study references.

\section{Conflicts of Interest}

The authors declare that there are no conflicts of interest. 


\section{References}

[1] L. L. Chen and J. Huang, "Design and implementation of public bicycle rental system service platform based on IOCP and JSON," Advanced Materials Research, vol. 998-999, no. 8, pp. 1100-1103, 2014.

[2] L. Ma, C. Jin, and Y. Huo, "Selection of logistics service modes in e-commerce based on multi-oligopolies Cournot competition," International Journal of Shipping and Transport Logistics, vol. 11, no. 4, pp. 354-383, 2019.

[3] Z. Ying, "Simulation of public art communication in colleges based on smart cloud platform and artificial intelligence algorithm," Journal of Intelligent and Fuzzy Systems, vol. 12, no. 3, pp. 1-11, 2020.

[4] P. Ping and Y. N. Petrenko, "Mobile robot navigation path algorithm in 3d industrial internet of thing (iot) environment based on $5 \mathrm{~g}$ mobile communication," System Analysis and Applied Information Science, vol. 9, no. 1, pp. 16-24, 2019.

[5] F. Pop, C. Dobre, B. C. Mocanu, O. M. Citoteanu, and F. Xhafa, "Trust models for efficient communication in mobile cloud computing and their applications to e-commerce," Enterprise Information Systems, vol. 10, no. 7, pp. 982-1000, 2015.

[6] F. Paolo, F. Alessandra, R. Stefano, E. Sisinni, D. Maffei, and M. Malara, "Impact of quality of service on cloud based industrial iot applications with OPCUA," Electronics, vol. 7, no. 7, pp. 109-112, 2018.

[7] W. Wei, X. Fan, H. Song, X. Fan, and J. Yang, "Imperfect information dynamic stackelberg game based resource allocation using hidden Markov for cloud computing," IEEE Transactions on Services Computing, vol. 11, no. 1, pp. 78-89, 2016.

[8] W. Li, I. Santos, F. C. Delicato et al., "System modelling and performance evaluation of a three-tier cloud of things," Future Generation Computer Systems, vol. 70, pp. 104-125, 2017.

[9] R. Filev, C. B. Lurbe, A. A. Baniya, and H. Hornbuckle, "IRRISENS: an IoT Platform based on microservices applied in commercial-scale crops working in a multi-cloud environment," Sensors, vol. 20, no. 24, pp. 63-71, 2020.

[10] J. X. Chen, "Based on the digital library mobile service platform construction and mobile reading," Journal of Library \& Information Sciences in Agriculture, vol. 26, no. 10, pp. 29-32, 2014.

[11] A. Samsudin and H. Cui, "Optimization of digitalized document verification using e-governance service delivery platform," International Journal of Computational Intelligence Research, vol. 14, no. 8, pp. 619-639, 2018.

[12] W. Cellary and S. Strykowski, "E-government based on cloud computing and service-oriented architecture," in Proceedings of the 3rd International Conference on Theory and Practice of Electronic Governance, Bogota, Columbia, November 2009.

[13] F. Chen, "The automatic positioning method for defect data of $5 \mathrm{~g}$ mobile communication based on cloud computing," International Journal of Autonomous and Adaptive Communications Systems, vol. 14, no. 4, pp. 12-16, 2021.

[14] S. Y. Jung, S. M. Yu, and S.-L. Kim, "Optimization of spectrum allocation and subsidization in mobile communication services," IEEE Transactions on Vehicular Technology, vol. 65, no. 10, pp. 8432-8443, 2016.

[15] H.-W. Kang, S.-J. Koh, S.-K. Lim, and T.-G. Kang, "TAC reconfiguration for paging optimization in LTE-based mobile communication systems," Computer Science and Its Applications, vol. 33, no. 10, pp. 677-682, 2015.
[16] S. Lee, J. Han, J. Kwon, and J. Kim, "Design and validation of service composition based on microservices architecture for cloud-native IoT-cloud services," KIISE Transactions on Computing Practices, vol. 26, no. 3, pp. 123-134, 2020.

[17] R. K. Ramasamy, F. F. Chua, and S. C. Haw, "Adaptive and dynamic service composition for cloud-based mobile application," Lecture Notes in Electrical Engineering, vol. 31, no. 5, pp. 963-973, 2016.

[18] F. Aulkemeier, M. A. Paramartha, M.-E. Iacob, and J. Van Hillegersberg, "A pluggable service platform architecture for e-commerce," Information Systems and E-Business Management, vol. 14, no. 3, pp. 469-489, 2016.

[19] P. Liu and W. He, "Research on the E-commerce operation performance of SMEs based on cloud computing service platform," Revista de la Facultad de Ingenieria, vol. 32, no. 3, pp. 500-509, 2017.

[20] Z. Zhe and J. H. Xu, "Design and implementation logistics cloud platform based on SOA," Applied Mechanics and Materials, vol. 610, no. 1, pp. 775-780, 2014.

[21] C. Li, J. Shen, and Y. Liu, "Study on architecture and implementation of port logistics information service platform based on cloud computing," New Journal of Chemistry, vol. 27, no. 3, pp. 1078-1083, 2015.

[22] Y. Y. Shen and Y. Qian, "A study of new E-commerce logistics mode based on cloud computing technology," Advanced Materials Research, vol. 1049-1050, no. 4, pp. 1848-1852, 2014.

[23] J. Li, G. Feng, W. Wei et al., "PSOTrack: a RFID-based system for random moving objects tracking in unconstrained indoor environment," IEEE Internet of Things Journal, vol. 5, no. 6, pp. 4632-4641, 2018.

[24] B. Andò, S. Baglio, V. Marletta, R. Crispino, and A. Pistorio, "A measurement strategy to assess the optimal design of an RFID-based navigation aid," IEEE Transactions on Instrumentation and Measurement, vol. 68, no. 7, pp. 2356-2362, 2018. 